\title{
Removal of malachite green from water by Firmiana simplex wood fiber
}

\author{
Xiangliang Pan \\ Xinjiang Institute of Ecology and Geography \\ Chinese Academy of Sciences \\ Urumqi 830011, China \\ Daoyong Zhang* \\ State Key Laboratory of Environmental Geochemistry \\ Institute of Geochemistry \\ Chinese Academy of Sciences \\ Guiyang, 550002, China \\ E-mail: zhang-daoyong@163.com
}

\begin{abstract}
Financial support: Knowledge Innovation Program of Chinese Academy of Sciences (KZCX2-YW-335 and KZCX2-YW-135), Program of 100 Distinguished Young Scientists of the Chinese Academy of Sciences , National Natural Science Foundation of China $(40673070,40872169)$ and 863 program project 2006AA06Z339 from MOST of China.
\end{abstract}

Keywords: adsorption, kinetics, malachite green, thermodynamics, wood fiber.

Abbreviations: MG: malachite green

This study shows that wood fiber of Phoenix tree (Firmiana simplex) is an effective adsorbent for malachite green (MG). MG sorption behavior onto the wood adsorbent was investigated in this study. Basic condition was favorable for MG adsorption to the adsorbent. The pseudo second order equation well described MG adsorption onto the wood adsorbent. The Freundlich Isotherm could describe the sorption data. The positive value of $\Delta \mathrm{H}^{0}$ showed that adsorption of malachite green onto the wood adsorbent was endothermic. The negative values of $\Delta G$ at various temperatures indicate the spontaneous nature of the adsorption process.

Malachite green (MG), a triphenylmethane dye, is used as an antifungal, anti-bacterial, and anti-parasitical therapeutic agent in aquacultures and animal husbandry. It is also widely used as a direct dye for silk, wool, jute and leather. Malachite green has detrimental effects on liver, gill, kidney, intestine and gonads of aquatic organisms (Srivastava et al. 2004). When it was inhaled or ingested by human, it may cause irritation to the gastrointestinal tract and even cancer (Garg et al. 2004). Contact of malachite green with skin causes irritation with redness and pain. Intermediate products after degradation of MG are also reported to be carcinogenic (Srivastava et al. 2004). Therefore, the use of malachite green in aquaculture was banned in many countries. However, MG in fishes, animal milk and other foodstuff is still detected due to illegal use of MG (Srivastava et al. 1995), which alarm the health hazards against human being.

Adsorption is the most commonly used method for color removal. Adsorption onto activated carbon is widely practiced for removal of dissolved dyes from wastewater. However, adsorbent-grade activated carbon is costprohibitive. So it is necessary to seek some alternative lowcost adsorbents that do not need pretreatment to replace activated carbon (Popuri et al. 2007; Vieira et al. 2007). Recently, a number of low-cost adsorbents for dye removal from mineral wastes (Yener et al. 2006), agricultural wastes, microbial biomass (Aksu, 2005) and higher plant biomass (Ho et al. 2005) were reported in the literature. Among them, biomaterials from higher plants seem to be one type of popular low-cost adsorbents because they usually have higher biomass compared with microbes and are easily available. For example, tree fern (Ho et al. 2005), orange peel (Arami et al. 2005), date pits (Banat et al. 2003), palm kernel fiber, sawdust (Garg et al. 2004), peanut hull (Gong et al. 2005), neem leaf (Bhattacharyy et al. 2003) and de-oiled soya (Mittal et al. 2005) were tested for treatment of dye-bearing wastewaters with different success.

Phoenix tree (Firmiana simplex) is a species of deciduous tree, which grows very fast and is widely spread in China. Its wood had no economic value. The aim of this study was to clarify adsorption behavior of phoenix tree wood fiber for removal of MG from water. The equilibrium, kinetics and thermodynamics of adsorption of MG from water to wood fiber were investigated.

\section{MATERIALS AND METHODS}

\section{Preparation of adsorbent and dye solution}

*Corresponding author 
Wood fiber of phoenix tree (Firmiana simplex) was powdered and sieved through a 100-mesh sieve. The powder was soaked in distilled water overnight and rinsed with several times till the wash water contains no color, monitored by a UV-vis spectrometer. The woody powder was air dried and stored in a desiccator for use. $\mathrm{pH}$ of the adsorbent was determined by Gindl and Tschegg's method (2002). Other physicochemical properties were characterized by adopting the standard procedures.

Analytical reagent $\mathrm{MG}, \mathrm{CI}=42000$, chemical formula= C50H52N4O8, $\lambda_{\max }=617 \mathrm{~nm}$, purity over 99\% was obtained from Shanghai Chemicals Co., China. Since the dye has high purity, we did not take the effect of impurity into account in our study. $1 \mathrm{~g} \mathrm{~L} \mathrm{~L}^{-1}$ stock solution was prepared with deionized water. All working solutions used in tests were prepared by appropriately diluting the stock solution to a pre-determined concentration. All other chemicals used in this study were analytical reagent.

\section{Sorption studies}

The adsorption of malachite green onto the adsorbent was investigated in batch experiments.

\section{Effect of initial solution $\mathrm{pH}$}

The effect of $\mathrm{pH}$ on dye malachite green sorption was evaluated by adding $0.25 \mathrm{~g}$ of adsorbent into flasks containing $100 \mathrm{ml}$ of $100 \mathrm{mg} \mathrm{L}^{-1}$ malachite green solutions at different initial $\mathrm{pH}(3-11) . \mathrm{pH}$ of the solutions was adjusted using $0.1 \mathrm{M} \mathrm{HCl} / \mathrm{NaOH}$. The adsorbent was added after $\mathrm{MG}$ solution $\mathrm{pH}$ was fixed. Flasks containing the adsorbent and MG solution were shaken at $300 \mathrm{rpm}$ and $25^{\circ} \mathrm{C}$ for $180 \mathrm{~min}$. Initial and equilibrium $\mathrm{pH}$ of solutions and residual malachite green concentrations were measured.

\section{Effect of adsorbent dosage}

Effect of adsorbent dosage was studied by adding different adsorbent doses (0.05-0.25 g) into flasks containing $100 \mathrm{ml}$ of $100 \mathrm{mg} \mathrm{L}^{-1}$ malachite green solutions. The $\mathrm{pH}$ of the solutions was preadjusted to 7 according to the result of the study on effect of pH. Flasks were shaken at $300 \mathrm{rpm}$ and $25^{\circ} \mathrm{C}$ for $180 \mathrm{~min}$. Initial and equilibrium $\mathrm{pH}$ of solutions and residual malachite green concentrations in solutions were measured.

\section{Kinetic study}

For kinetic sorption experiment, $1.25 \mathrm{~g}$ of dry adsorbents were added to flasks containing $500 \mathrm{ml}$ of $100 \mathrm{mg} \mathrm{L}^{-1}$ malachite green-bearing solution with $\mathrm{pH}$ adjusted to 7 . Flasks were shaken at $300 \mathrm{rpm}$ at predetermined temperature. Aliquot amounts of solution were taken, periodically. Residual malachite green concentrations in solutions were measured.

\section{Isothermal and thermodynamic study}

For isotherm analysis, adsorption experiments were conducted by varying the initial malachite green concentration from $10 \mathrm{mg} / \mathrm{l}$ to $500 \mathrm{mg} \mathrm{L} \mathrm{m}^{-1} .0 .25 \mathrm{~g}$ of dry adsorbent were added to flasks containing $100 \mathrm{ml}$ of malachite green-bearing solution with $\mathrm{pH}$ preadjusted to 7 . Flasks were shaken at $300 \mathrm{rpm}$ and predetermined temperature for $180 \mathrm{~min}$. Residual malachite green concentrations in solutions were measured.

\section{Analytical methods}

The samples were centrifuged and malachite green concentrations in supernatant were determined by measuring the absorbance using a spectrophotmeter (UV2000, Unico, Shanghai, China). pH was measured using a $\mathrm{pH}$ meter.

\section{RESULTS AND DISCUSSION}

\section{Physicochemical properties of the adsorbent}

The physico-chemical characteristics of the adsorbent were: apparent density $1.36 \mathrm{~g} / \mathrm{ml}$; surface area $226.5 \mathrm{~m}^{2} / \mathrm{g}$; Cation exchange capacity (CEC) 0.87 meq/g dry matter; $\mathrm{pH}$ 5.1; and EC $0.11 \mathrm{mS} / \mathrm{cm}$.

\section{Effect of initial pH}

Figure 1 shows that adsorption percentage of MG increased with increasing $\mathrm{pH}$. The maximum of adsorption

Table 1. Pseudo-first and pseudo-second-order constants and values of $R^{2}$ for MG adsorption to wood adsorbent.

\begin{tabular}{|c|c|c|c|c|c|c|c|c|}
\hline \multirow[b]{2}{*}{$\begin{array}{c}q_{e, \exp } \\
\left(\mathrm{mg} \mathrm{g}^{-1}\right)\end{array}$} & \multicolumn{3}{|c|}{ First order } & \multicolumn{5}{|c|}{ Second order } \\
\hline & $\begin{array}{c}q_{1, \mathrm{cal}} \\
\left(\mathrm{mg} \mathrm{g}^{-1}\right)\end{array}$ & $\begin{array}{c}k_{1} \\
\left(\min ^{-1}\right)\end{array}$ & $R^{2}$ & $\begin{array}{c}q_{2, \text { cal }} \\
\left(\mathrm{mg} \mathrm{g}^{-1}\right)\end{array}$ & $\begin{array}{c}k_{2} \\
\left(\mathrm{~g} \mathrm{mg}^{-1}\right. \\
\left.\mathrm{min}^{-1}\right)\end{array}$ & $\begin{array}{c}u \\
\left(\mathrm{mg} \mathrm{g}^{-1} \min ^{-}\right)\end{array}$ & $\begin{array}{c}t_{1 / 2} \\
(\mathrm{~min})\end{array}$ & $r$ \\
\hline 36.0 & 11.98 & 0.022 & 0.85 & 36.38 & 0.0064 & 8.52 & 4.29 & 0.999 \\
\hline
\end{tabular}


Removal of malachite green from water by Firmiana simplex wood fiber

Table 2. Isothermal parameters of ethyl violet adsorption onto the wood adsorbent.

\begin{tabular}{|c|c|c|c|}
\hline \multirow{2}{*}{$\begin{array}{c}\text { Temperature } \\
\text { (K) }\end{array}$} & \multicolumn{3}{|c|}{ Freundlich parameters } \\
\hline 278 & $\boldsymbol{K}_{\boldsymbol{F}}\left(\mathbf{m g ~ g}^{-\mathbf{1}}\right)$ & $\mathbf{1 / n}$ & $\boldsymbol{r}$ \\
\hline 288 & 0.288 & 0.919 & 0.975 \\
\hline 298 & 0.457 & 0.878 & 0.978 \\
\hline 308 & 0.706 & 0.746 & 0.975 \\
\hline & 0.813 & 0.714 & 0.977 \\
\hline
\end{tabular}

percentage of malachite green was observed at $\mathrm{pH} 11$. At lower $\mathrm{pH}$, the number of positively charged adsorbent surface sites increased at the expense of the number of negatively charged surface sites. The carboxylic groups of MG ( $\mathrm{pKa}=10.3$ ) were protonated and had high positive charge density at a lower $\mathrm{pH}$ (Garg et al. 2003; Crini et al. 2007). Consequently, electrostatic repulsion between the positively charged surface and the positively charged dye molecule increased with increasing solution $\mathrm{pH}$ and resulted in the decreasing of adsorption capacity of MG to the adsorbent with increasing of $\mathrm{pH}$. In addition, the competition of $\mathrm{H}^{+}$with the cationic dye molecules due to the presence of excess $\mathrm{H}^{+}$also decreased the adsorption (Porkodi and Kumar, 2007). On the contrary, the surface of the adsorbent was negatively charged at higher $\mathrm{pH}$, which favored for adsorption of the positively charged dye cations through electrostatic force of attraction. The adsorption of MG to wood fiber consequently increased with increasing of $\mathrm{pH}$ values.

A similar trend was observed for the adsorption of MG to cyclodextrin-based adsorbent (Crini et al. 2007), anaerobic granular sludge (Cheng et al. 2008), de-oiled soya (Mittal et al. 2005), hen feathers (Mittal, 2006), rattan sawdust (Hameed and El-Khaiary, 2008a; Hameed and El-Khaiary, 2008b) and rice straw.

Effect of adsorbent dosage. It is evident from Figure 2 that the removal percentage of malachite green increased on the increasing of the adsorbent dosage. This can be attributed to the increase in surface area with a high dosage of the adsorbent. On the contrary, the sorption capacity decreased from $142.4 \mathrm{mg} / \mathrm{g}^{-1}$ to $35.6 \mathrm{mg} / \mathrm{g}^{-1}$ as adsorbent dosage increased from $0.05 \mathrm{~g}$ to $0.25 \mathrm{~g}$. The decrease in sorption capacity may be attributed to the splitting effect of flux (concentration gradient) between sorbate and adsorbent, with increasing adsorbent concentration causing a decrease in amount of malachite green adsorbed onto unit weight of adsorbent.

\section{Sorption kinetics}

Study of sorption kinetics can provide important information on sorption rate and the factors affecting the sorption rate, which is extremely important in designing batch sorption systems. Time courses of malachite green adsorption onto woody fiber were given in Figure 3a. In the present study, pseudo-first order and pseudo-second order models were employed to analyze the kinetics of malachite green adsorption onto the adsorbent.

\section{First-order model}

The pseudo-first order equation of Lagergren is generally expressed as follows (Ho and McKay, 1999):

$$
d q_{t} / d t=k_{1}\left(q_{1}-q_{t}\right)
$$

where $q_{1}$ and $q_{t}$ are the amount of malachite green adsorbed per unit weight of adsorbent at equilibrium and at time $t$, respectively (mg/g) and $k_{1}$ the rate constant of pseudo-first order sorption $(\mathrm{l} / \mathrm{min})$. given the boundary conditions for $t=0, q_{t}=0$, the equation(1) can be integrated to give (Ho and McKay, 1999)

$$
\log \left(q_{1^{-}} q_{t}\right)=\log q_{1^{-}}\left(k_{1} / 2.303\right) t
$$

If the sorption process can be described by pseudo-first order equation, there should be good linear relationship between $\log \left(q_{1}-q\right)$ and $t$.

In the present study, the plot of $\log \left(q_{1}-q_{t}\right)$ versus time $t$ and the relationship was not linear over the entire time range (Figure $3 b$ ), indicating that more than one mechanism involved in adsorption. The $q_{1 \text {, cal }}$ obtained from first-order equation was much different from the expected values $\left(q_{\exp }\right)$ (Table 1). 


\begin{tabular}{|c|c|c|c|c|c|}
\hline \multirow{2}{*}{$\begin{array}{c}\Delta \mathrm{H}^{0} \\
\left(\mathrm{~kJ} \mathrm{~mol}^{-1}\right)\end{array}$} & \multirow{2}{*}{$\underset{\left(\mathrm{J} \mathrm{mol}^{-1}\right)}{\left.\Delta \mathrm{S}^{0}\right)}$} & \multicolumn{4}{|c|}{$\Delta G\left(\mathrm{KJ} \mathrm{mol}^{-1}\right)$} \\
\hline & & $278 K$ & $288 \mathrm{~K}$ & $298 K$ & $308 K$ \\
\hline 61.4 & 234.3 & -3.65 & -5.99 & -8.33 & -10.67 \\
\hline
\end{tabular}

\section{Second-order model}

If the rate of sorption is a second order mechanism, the pseudo-second order chemisorption kinetic rate equation is expressed as (Ho and McKay, 1999)

$$
d q_{t} / d t=k_{2}\left(q_{2}-q_{t}\right)^{2}
$$

Where $q_{2}$ is the amount of malachite green adsorbed at equilibrium ( $\left.\mathrm{mg} \mathrm{g}^{-1}\right), k_{2}$ is pseudo-second order rate constant $\left(\mathrm{g} \mathrm{mg}^{-1} \mathrm{~min}^{-1}\right)$, and $q_{t}$ is the amount of malachite green adsorbed per unit weight of adsorbent at time $t$. After integrating and applying boundary conditions for $t=0, q_{t}=0$, equation (3) becomes

$$
t / q_{t}=1 /\left(k_{2} q_{2}^{2}\right)+t / q_{2}
$$

The rate constant $k_{2}$ can be obtained from the intercept of the linearized pseudo-second order rate equation. If the pseudo-second order equation can fit the sorption data, there should be good linearity between $t / q_{t}$ and $t$. when $t \rightarrow 0$, the initial sorption rate $u$ can be defined as

$$
u=k_{2} q_{2}^{2}
$$

Half-adsorption time $\left(t_{1 / 2}\right)$ is the time required for the adsorption to take up half as much malachite green as its equilibrium value. This time is an indicator for the adsorption rate. It was calculated from the following equation:

$$
t_{1 / 2}=1 / k_{2} q_{2}
$$

Figure 3c showed that the pseudo-second order equation was satisfactorily applicable to all the sorption data $(r=0.999)$. The pseudo second-order sorption constants were summarized in Table 1 . The $q_{2 \text {, cal }}$ calculated from second-order equation was close to the expected values.

MG adsorption kinetics to cyclodextrin-based adsorbent (Crini et al. 2007), Pithophora spp. (Kumar et al. 2005) and carbon (Zhang et al. 2008) were also reported to follow the pesudo second-order equation.

\section{Sorption isotherms}

The Freundlich isotherm is a nonlinear model and is shown to be consistent with exponential distribution of active centres, characteristic of heterogeneous surfaces. It is usually expressed as follows:

$$
q_{e}=k_{F} \mathrm{C}_{e}^{1 / n}
$$

where $q_{e}$ is the amount of malachite green adsorbed, $\mathrm{mg} / \mathrm{g}$ ${ }^{1}$ (dry mass); $C_{e}$ is the equilibrium malachite green concentration in solution, $\mathrm{mg} \mathrm{L}^{-1} ; k_{F}$ and $n$ are rate constants, being indicative of the extent of adsorption and the degree of nonlinearity between solution and concentration, respectively. A high value of $n$ is indicative of good adsorption over the entire range of concentrations studied, while small $n$ is indicative of good adsorptin at high concentrations but much less at lower concentrations. A higher value of $k_{F}$ indicates a higher capacity for adsorption than a lower value.

The Freundlich equation describing malachite green adsorption by the wood adsorbent was illustrated in Figure 4, and the Freundlich constants calculated from the linear equations were summarized in Table 2. The Freundlich equations could describe the sorption. However, Kumar and Sivanesan (2007) demonstrated that sorption process of malachite onto rubber wood could not well represented by the linear Freundlich equation but could be well described by the nonlinear Freundlich equation.

The values of the exponent $1 / n$ were in the range of $0-1$, indicating favorable adsorption at all temperatures tested. The value of $K_{F}$ increased on increasing of temperature, indicating that higher temperature favored malachite green sorption onto the wood adsorbent. The MG sorption capacity to wood fiber increased on increasing of the temperature. At an initial malachite green concentration of $100 \mathrm{mg} / \mathrm{l}$, the sorption capacity steadily increased from 32.6 $\mathrm{mg} / \mathrm{g}^{-1}$ at $278 \mathrm{~K}$ to $36.6 \mathrm{mg} / \mathrm{g}^{-1}$ at $308 \mathrm{~K}$, indicating that the process is endothermic in nature and higher temperature was favorable for malachite green adsorption onto adsorbent.

\section{Thermodynamic studies}

Analysis of thermodynamics of equilibrium sorption data can give more important information on sorption process. In the present study, thermodynamic parameters were calculated by using the equation (8)

$$
\ln K_{d}=\Delta S^{0} / R-\Delta H^{0} / R T
$$

where $K_{d}$ is the distribution coefficient $\left(\mathrm{ml} / \mathrm{g}^{-1}\right), \Delta H^{0}, \Delta S^{0}$, and $T$ are the enthalpy, entropy, and temperature in kelvin, respectively, and $R$ is the gas constant. $\Delta H^{0}$ and $\Delta S^{0}$ were 
Table 4. Comparison of adsorption capacities of various adsorbents for MG

\begin{tabular}{|c|c|c|c|}
\hline Adsorbent & $\begin{array}{c}q_{m} \text { or experimental } \\
\text { sorption capacity } \\
\left(\mathrm{mg} \mathrm{g}^{-1}\right)\end{array}$ & $\begin{array}{l}\text { Temperature } \\
\left({ }^{\circ} \mathrm{C}\right)\end{array}$ & Reference \\
\hline Bamboo-based activated carbon & 263.6 & 30 & Hameed and El-Khaiary, 2008a \\
\hline Activated carbon & $466-565$ & $32-60$ & Kumar, 2006 \\
\hline $\begin{array}{l}\text { Groundnut shell based activated } \\
\text { carbon }\end{array}$ & 222.2 & 30 & Malik et al. 2007 \\
\hline Commercial activated carbon & 8.27 & 30 & Mall et al. 2005 \\
\hline Laboratory grade activated carbon & 42.18 & 30 & Mall et al. 2005 \\
\hline Arundo donax root carbon & 8.69 & 30 & Zhang et al. 2008 \\
\hline Bentonite & 178.6 & $25 \pm 2$ & Bulut et al. 2008 \\
\hline rattan sawdust & 62.7 & 25 & Hameed and El-khaiary, 2008b \\
\hline Rubber wood sawdust & $25.8-36.3$ & - & Kumar and Sivanesan, 2007 \\
\hline Functionalized sawdust & $85.5-196.1$ & $20-40$ & Gong et al. 2009 \\
\hline Dead tree leaves & $77.5-89.4$ & $25-45$ & Hamdaouia et al. 2008 \\
\hline Hen feather & $10.3-10.7$ & $30-50$ & Mittal, 2006 \\
\hline Lemon peel & $3.2-51.7$ & 32 & Kumar, 2007 \\
\hline Jute fiber carbon & 136.58 & 30 & Porkodi and Kumar, 2007 \\
\hline Firmiana simplex wood fiber & $>142.4$ & 25 & This study \\
\hline
\end{tabular}

*Unless stated; LOQ = Limit of quantification, lactic acid $=0.03 \%$; mean value and standard deviation of three determinations are presented.

obtained from the slope and intercept of the plot of $\ln K_{\mathrm{d}}$ against $1 / T$ (Figure 5 ). Gibbs free energy $\Delta G$ was calculated using the equation (9)

$$
\Delta G=\Delta H^{0}-T \Delta S^{0}
$$

The values of the thermodynamic parameters for the sorption of malachite green onto adsorbent are given in Table 3. The positive value of $\Delta H^{0}$ showed that adsorption of malachite green onto the wood adsorbent was endothermic. The negative values of $\Delta G$ at various temperatures indicate the spontaneous nature of the adsorption process. $\Delta G$ decreases with increased temperature indicated that the adsorption was more favorable at higher temperature. The positive value of $\Delta S^{0}$ indicated that the adsorption process was irreversible and random at the solid/liquid interface during the sorption of malachite green onto the wood adsorbent. In addition, the positive value of $\Delta S^{0}$ suggested some structural change of malachite green and the wood adsorbent (Gupta, 1998) and favored complexion and sorption stability (Donat et al. 2005). Similar results were also observed on carbon prepared from Arundo donax root (Zhang et al. 2008) and de-oiled soya (Mittal et al. 2005), bentonite (Bulut et al. 2008) and hen feathers (Mittal, 2006).

\section{Comparison with other adsorbents for MG}

Many adsorbents for MG removal, including activated carbon, various biosorbents, minerals, were reported in the literature (e.g., Mall et al. 2005; Kumar, 2006; Malik et al. 2007; Bulut et al. 2008; Zhang et al. 2008). Part of the data of MG sorption capacity (values of $q_{m}$ derived from the Langmuir equation) of various adsorbents, especially the low-cost adsorbents, was summarized in Table 4. In the present study, the experimental value was used due to 
failure of the Langmuir equation to describe the isothermal sorption data. It was found that Firmiana Simplex wood fiber is an excellent adsorbent for MG. Activated carbon, sometimes, was more effective in sorption of MG than this woody adsorbent. However, activated carbon is costprohibitive since a great deal of energy would be consumed during production of activated carbon. On the contrary, Firmiana simplex wood almost costs nothing since it has little economic value and can be directly used as adsorbent without further procedures. In this sense, Firmiana simplex wood fiber is an excellent adsorbent for MG.

\section{CONCLUDING REMARKS}

The wood adsorbent was an excellent adsorbent for malachite green. The sorption kinetics followed the pseudo second order equation, indicating that several processes were involved in malachite green sorption onto the wood adsorbent. Basic condition was favorable for MG adsorption to the adsorbent. The Freundlich Isotherm satisfactorily described the sorption data. The MG adsorption was a spontaneous endothermic process.

Since Firmiana simplex grows widely in the world and rapidly with great biomass, has little economic values, and has excellent adsorption capacity for MG, Firmiana simplex wood fiber should be a promising and costeffective adsorbent for MG removal in industry. Further studies on quantitative characterization of this adsorbent and involved mechanisms, and feasibility of using this adsorbent for other triphenylmethane dyes and for its possible industrial application are needed.

\section{ACKNOWLEDGEMENTS}

We would like to express our gratitude to the three anonymous reviewers for their valuable comments that improved the quality of this manuscript.

\section{REFERENCES}

AKSU, Zümriye. Application of biosorption for the removal of organic pollutants: a review. Process Biochemistry, March 2005, vol. 40, no. 3-4, p. 997-1026.

ARAMI, Mokhtar; YOUSEFI, Limaee Nargess; MAHMOODI, Niyaz Mohammad and TABRIZI, Nooshin Salman. Removal of dyes from colored textile wastewater by orange peel adsorbent: equilibrium and kinetic studies. Journal of Colloid and Interface Science, August 2005, vol. 288, no. 2, p. 371-376.

BANAT, Fawzi; AL-ASHEH, Sameer and ALMAKHADMEH, Leema. Evaluation of the use of raw and activated date pits as potential adsorbents for dye containing waters. Process Biochemistry, October 2003, vol. 39, no. 2, p. 193-202.

BHATTACHARYYA, Krishna G. and SARMA, Arunima. Adsorption characteristics of the dye, Brilliant green, on
Neem leaf powder. Dyes and Pigments, June 2003, vol. 57, no. 3, p. 211-222.

BULUT, Emrah; OZACAR, Mahmut and SENGIL, I. Ayhan. Adsorption of malachite green onto bentonite: equilibrium and kinetic studies and process design. Microporous and Mesoporous Materials, November 2008, vol. 115, no. 3, p. 234-246.

CHENG, Wen; WANG, Shu-Guang; LU, Lei; GONG, Wenxin; LIU, Xianwei; GAO, Baoyu and ZHANG, Huayong. Removal of malachite green (MG) from aqueous solutions by native and heat-treated anaerobic granular sludge. Biochemical Engineering Journal, May 2008, vol. 39, no.1, p. 538-546.

CRINI, Gregorio; PEINDY, Harmel Ndongo; GIMBERT, Frédéric and ROBERT, Frederic. Removal of C.I. Basic Green 4 (Malachite Green) from aqueous solutions by adsorption using cyclodextrin-based adsorbent: kinetic and equilibrium studies. Separation and Purification Technology, February 2007, vol. 53, no.1, p. 97-110.

DONAT, R.; AKDOGAN, A.; ERDEM, E. and CETISLI, $\mathrm{H}$. Thermodynamics of $\mathrm{Pb}^{2+}$ and $\mathrm{Ni}^{2+}$ adsorption onto natural bentonite from aqueous solutions. Journal of Colloid and Interface Science, June 2005, vol. 286, no. 1, p. 43-52.

GARG, V.K.; KUMAR, R. and GUPTA, R. Removal of malachite green dye from aqueous solution by adsorption using agro-industry waste: a case study of Prosopis cineraria. Dyes and Pigments, July 2004, vol. 62, no. 1, p. $1-10$.

GARG, V.K.; GUPTA, R.; YADAV, A.B. and KUMAR, R. Dye removal from aqueous solution by adsorption on treated sawdust. Bioresource Technologies, September 2003, vol. 89, no. 2, p. 121-124.

GINDL, Milojka and TSCHEGG, Stefanie. Significance of the acidity of wood to the surface free energy components of different wood species. Langmuir, March 2002, vol. 18, no. 8, p. 3209-3212.

GONG, Renmin; SUN, Yingzhi; CHEN, Jian; LIU, Huijun and YANG, Chao. Effect of chemical modification on dye adsorption capacity of peanut hull. Dyes and Pigments, December 2005, vol. 67, no. 3, p. 175-181.

GONG, Renmin; FENG, Min; ZHAO, Jiajing; CAI, Wenkai and LIU, Lingling. Functionalization of sawdust with monosodium glutamate for enhancing its malachite green removal capacity. Bioresource Technology, January 2009, vol. 100, no. 2, p. 975-978.

GUPTA, Vinod K. Equilibrium uptake, sorption dynamics, process development, and column operations for the removal of copper and nickel from aqueous solution and wastewater using activated slag, a low-cost adsorbent. 
Industrial and Engineering Chemical Research,January 1998, vol. 37, no. 1, p. 192-202.

HAMEED, B.H. and EL-KHAIARY, M.I. Equilibrium, kinetics and mechanism of malachite green adsorption on activated carbon prepared from bamboo by $\mathrm{K}_{2} \mathrm{CO}_{3}$ activation and subsequent gasification with $\mathrm{CO}_{2}$. Journal of Hazardous Materials, September 2008a, vol. 157, no. 2-3, p. 344-351.

HAMEED, B.H. and EL-KHAIARY, M.I. Malachite green adsorption by rattan sawdust: Isotherm, kinetic and mechanism modeling. Journal of Hazardous Materials, November 2008b, vol. 159, no. 2-3, p. 574-579.

HAMDAOUIA,Oualid; SAOUDI, Fethi; CHIHA, Mahdi and NAFFRECHOUX, Emmanuel. Sorption of malachite green by a novel sorbent, dead leaves of plane tree: equilibrium and kinetic modeling. Chemical Engineering Journal, September 2008, vol. 143, no. 1-3, p. 73-84.

HO, Y.S. and MCKAY, G.A kinetic study of dye sorption by biosorbent waste product pith. Resources, Conservation and Recycling, March 1999, vol. 25, no. 3, p. 171-193

HO, Yuh-Shan; CHIANG, Tzu-Hsuan and HSUEH, YuMei. Removal of basic dye from aqueous solution using tree fern as a bioadsorbent. Process Biochemistry, January 2005, vol. 40, no. 1, p. 119-124.

KUMAR, K. Vasanth. Optimum sorption isotherm by linear and non-linear methods for malachite green onto lemon peel. Dyes and Pigments, 2007, vol. 74, no. 3, p.595597.

KUMAR, K.V. and SIVANESAN, S. Isotherms for Malachite Green onto rubber wood (Hevea brasiliensis) sawdust: comparison of linear and non-linear methods. Dyes and Pigments, 2007, vol. 72, no. 1, p. 124-129.

KUMAR, K. Vasanth. Comparative analysis of linear and non-linear method of estimating the sorption isotherm parameters for malachite green onto activated carbon. Journal of Hazardous Materials, August 2006, vol. 136, no. 2, p. 197-20.

KUMAR, K.V.; SIVANESAN, S. and RAMAMURTHY, V. Adsorption of malachite green onto Pithophora sp., a fresh water algae: equilibrium and kinetic modeling. Process Biochemistry, July 2005, vol. 40, no. 8, p. 28652872.

MALIK, R.; RAMTEKE, D.S. and WATE, S.R. Adsorption of malachite green on groundnut shell waste based powdered activated carbon. Waste Management, 2007, vol. 27, no. 9, p. 1129-1138.

MALL, Indra Deo; SRIVASTAVA, Vimal Chandra; AGARWAL, Nitin Kumar and MISHRA, Indra Mani. Adsorptive removal of malachite green dye from aqueous solution by bagasse fly ash and activated carbon-kinetic study and equilibrium isotherm analyses. Colloids and Surfaces A: Physicochemical and Engineering Aspects, August 2005, vol. 264, no. 1-3, p. 17-28.

MITTAL, A.; KRISHNAN, L. and GUPTA, V.K. Removal and recovery of malachite green from wastewater using an agricultural waste material, de-oiled soya. Separation and Purification Technology, May 2005, vol. 43, no. 2, p. 125133.

MITTAL, Alok. Adsorption kinetics of removal of a toxic dye, Malachite Green, from wastewater by using hen feathers. Journal of Hazardous Materials, May 2006, vol. 133, no. 1-3, p.196-202.

POPURI, Srinivasa Rao; JAMMALA, Ajithapriya; REDDY, Kachireddy Venkata Naga Suresh and ABBURI, Krishnaiah. Biosorption of hexavalent chromium using tamarind (Tamarindus indica) fruit shell-a comparative study. Electronic Journal of Biotechnology, July 2007, vol. 10, no. 3, p. 358-367.

PORKODI, K. and KUMAR, K.V. Equilibrium, kinetics and mechanism modeling and simulation of basic and acid dyes sorption onto jute fiber carbon: eosin yellow, malachite green and crystal violet single component systems. Journal of Hazardous Materials,May 2007, vol. 143, no. 1-2, p. 311-327.

SRIVASTAVA, S.J.; SINGH, N.D.; SRIVASTAVA, A.K. and SINHA, R. Acute toxicity of malachite green and its effects on certain blood parameters of a catfish, Heteropneustes fossilis. Aquatic Toxicology, March 1995, vol. 31, no. 3, p. 241-247.

SRIVASTAVA, S.; SINHA, R. and ROY, D. Toxicological effects of malachite green. Aquatic Toxicology, February 2004, vol. 66, no. 3, p. 319-329

VIEIRA, Denise Mesquita; DA COSTA, Antonio Carlos Augusto; HENRIQUES, Cristiane Assumpção; CARDOSO, Vicelma Luiz andDE FRANCA, Francisca Pessôa. Biosorption of lead by the brown seaweed Sargassum filipendula - batch and continuous pilot studies. Electronic Journal of Biotechnology, July 2007, vol. 10, no. 3, p. 368-375.

YENER, Julide; KOPAC, Turkan; DOGU, Gulsen and DOGU, Timur. Adsorption of basic Yellow 28 from aqueous solutions with clinoptilolite and amberlite. Journal of Colloid and Interface Science, February 2006, vol. 294, no. 2, p. 255-264.

ZHANG, Jian; LI, Yan; ZHANG, Chenglu and JING, Yuming. Adsorption of malachite green from aqueous solution onto carbon prepared from Arundo donax root. Journal of Hazardous Materials, February 2008, vol. 150, no. 3, p. 774-782. 


\section{APPENDIX}

\section{FIGURES}

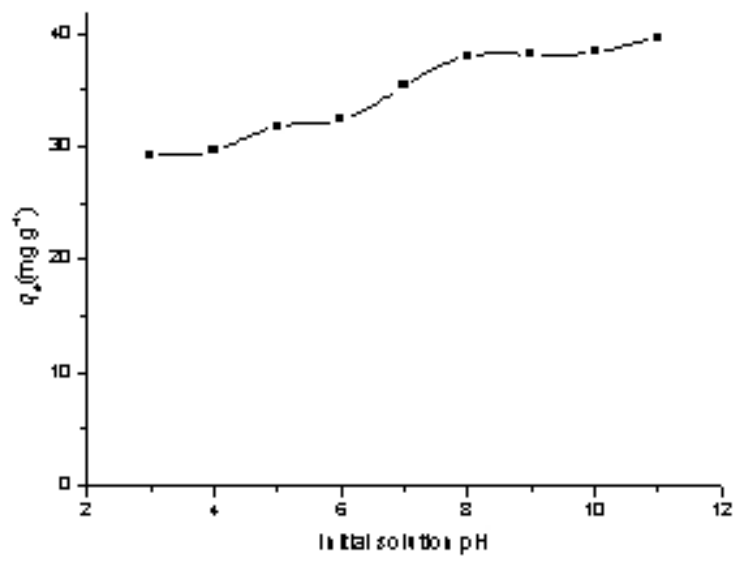

Figure 1. Effect of initial pH on MG removal by the wood fiber.

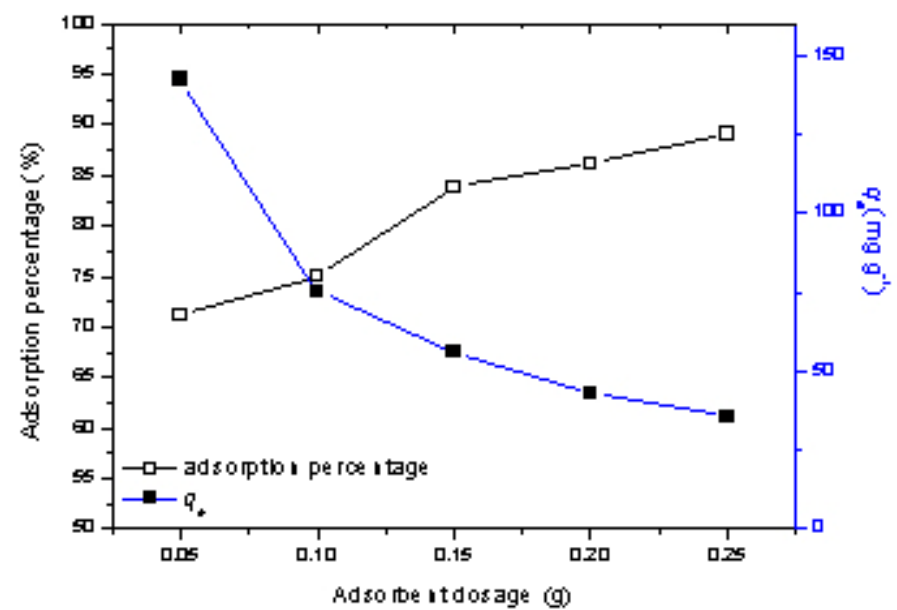

Figure 2. Effect of adsorbent dosage on MG adsorption percentage and sorption capacity. 


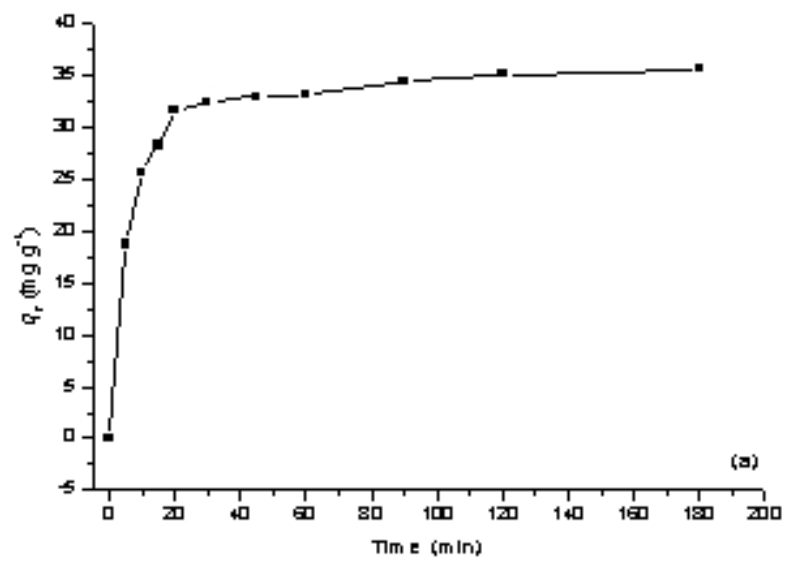

Figure 3 (a)

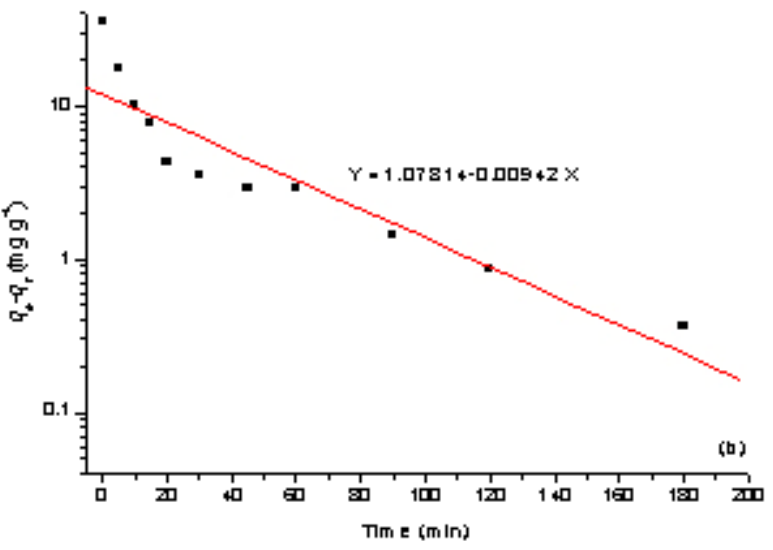

Figure 3 (b)

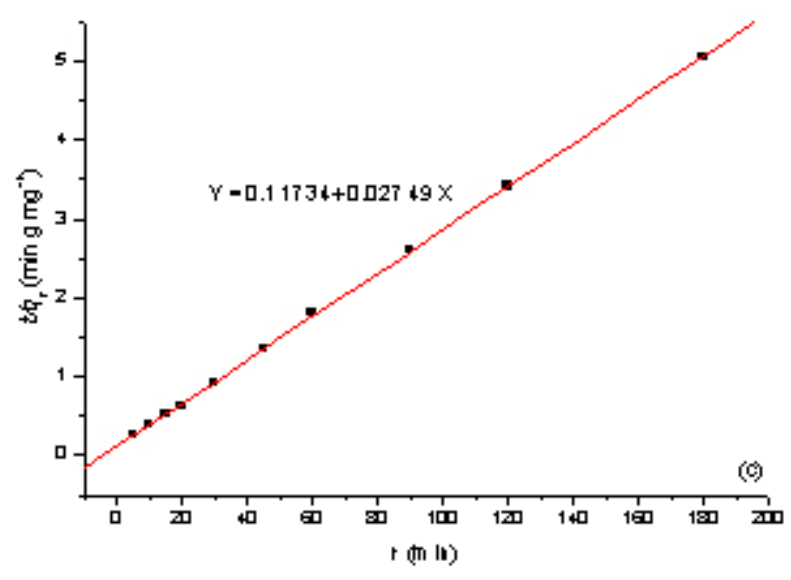

Figure 3 (c)

Figure 3. Time courses of MG adsorption onto the wood fiber. 
Pan, X. and Zhang, D.

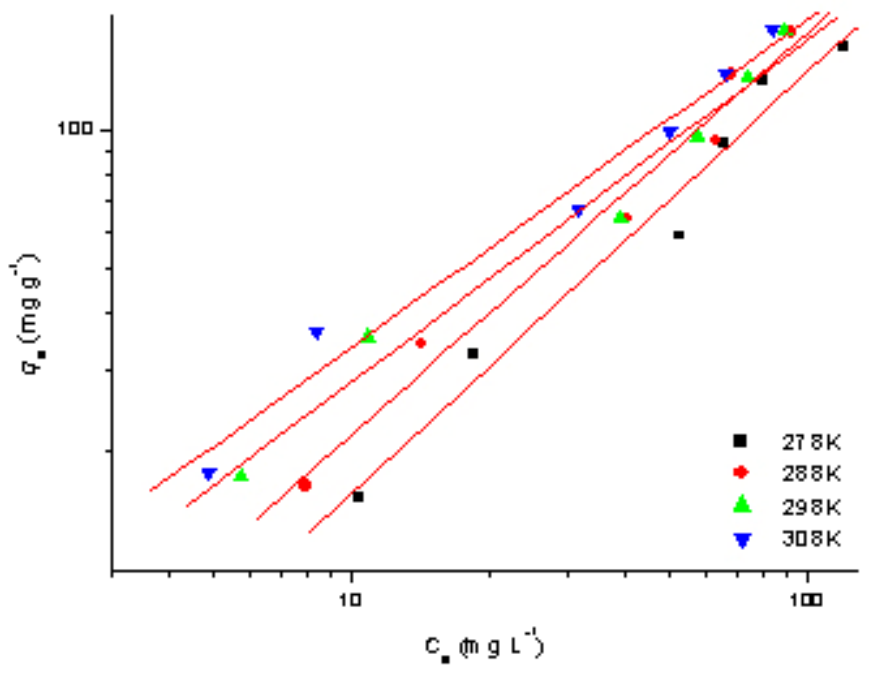

Figure 4. Freundlich Isotherm for the adsorption of MG to the wood fiber.

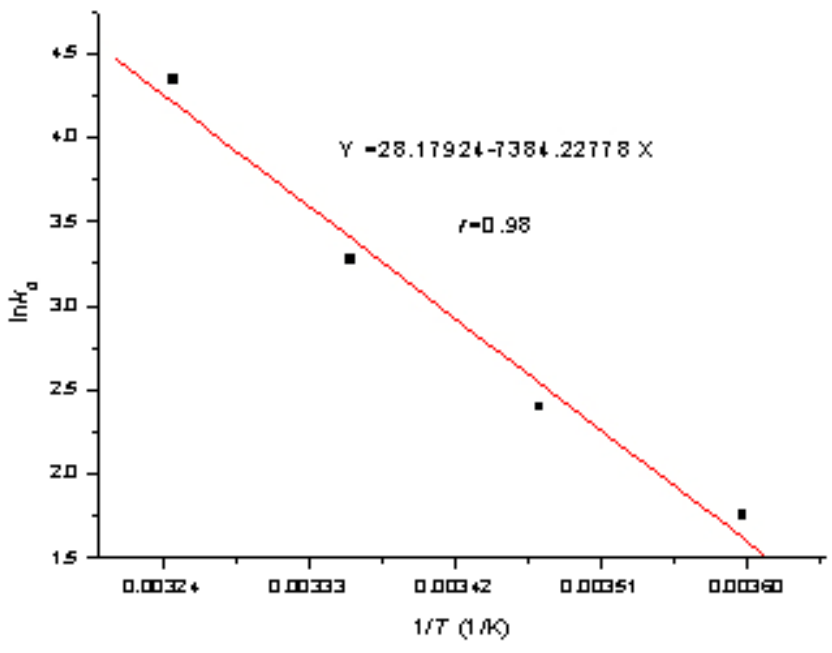

Figure 5. The plot of Ink against 1/T (1/K). 